\title{
An Improved PWM Technique to Achieve Continuous Input Current in Common-Ground Transformerless Boost Inverter
}

\author{
Sze Sing Lee, Senior Member, IEEE, Yam P. Siwakoti, Senior Member, IEEE, Chee Shen Lim, Senior \\ Member, IEEE, and Kyo-Beum Lee, Senior Member, IEEE
}

\begin{abstract}
A latest common-ground transformerless inverter for photovoltaic (PV) system has demonstrated its superiority over its existing counterpart due to its merits of single-stage structure and voltage boost capability. The exploited modulation scheme, however, led to discontinuous input current that draws high peak current from the source and causes high input power fluctuation in the converter. Such discontinuous and high peak current are detrimental to the PV source. Addressing this concern, this letter proposes a new modulation technique that achieves continuous input current with reduced peak magnitude while in the meantime ensures a good quality ac output voltage. Simulation and experimental results of a laboratory prototype are provided to verify the effectiveness of the proposed modulation technique.
\end{abstract}

Index Terms-Common-ground, continuous input current, PWM technique, transformerless inverter, voltage-boosting.

\section{INTRODUCTION}

$\mathrm{T}$ RANSFORMERLESS inverter which discards the need of bulky and costly transformer has recently emerged as an attractive candidate for grid-connected photovoltaic (PV) systems [1], [2]. Despite the higher compactness, the absence of transformer in the configuration gives rise to insufficient voltage isolation between the PV array and the grid. The resulting parasitic capacitance of the PV cells thereby induces the risk of leakage current [3].

To overcome the demerit of leakage current, the transformerless inverter topology is configured such that there is a common ground between the dc source and ac output, as shown in Fig. 1. Notice that the parasitic capacitor at the positive terminal of PV cell is clamped across the solar array whereas the one at the negative terminal is shorted to ground. The high frequency common mode voltage is eliminated, thus suppressing the leakage current across both parasitic capacitors.

The common-ground transformerless inverters in existing literatures were mainly established by considering the integration of switched-capacitor circuit [4]-[6]. An electrolytic

S. S. Lee is with the Newcastle Research and Innovation Institute, Newcastle University, Singapore (e-mail: szesinglee@gmail.com).

Y. P. Siwakoti is with the Faculty of Engineering and IT, University of Technology Sydney, Australia (e-mail: siwakoti.engg@gmail.com).

C. S. Lim is with the School of Electronics and Computer Science, University of Southampton, Malaysia (e-mail: C.S.Lim@soton.ac.uk).

K. B. Lee is with the Power Electronics Lab, Ajou University, South Korea (e-mail: kyl@ajou.ac.kr).

Corresponding author: Sze Sing Lee capacitor is charged from the dc source during its positive and zero voltage level, before it supplies power to the load during its negative voltage level. Note that the capacitors in switchedcapacitor circuit are charged by connecting them in parallel with the dc source [7]-[9]. Voltage difference induced between the capacitor and dc source causes significant current spikes. Another drawback of these topologies is their unity voltage gain. Without the voltage boosting capability, a front-end dc-dc boost converter is essential to cater for the high dc-link voltage requirement of at least the ac peak voltage, thus constitutes the commonly used two-stage power conversion system.

Being different from the existing transformerless inverters, an innovative common-ground topology which is capable of single-stage dc-ac power conversion was recently proposed in [10] and its circuit diagram is illustrated in Fig. 2. While retaining the inherent leakage current suppression ability in a common-ground inverter configuration, the established topology is superior such that it gains added advantages of higher compactness and voltage boosting capability. However, the energy storage inductor is unable to operate in full continuous mode with the modulation technique discussed in [10]. As a result, the input current is discontinuous and its peak value is excessively high. This undoubtedly results in high input power fluctuation and high current stress on power switches which made it not viable for PV applications.

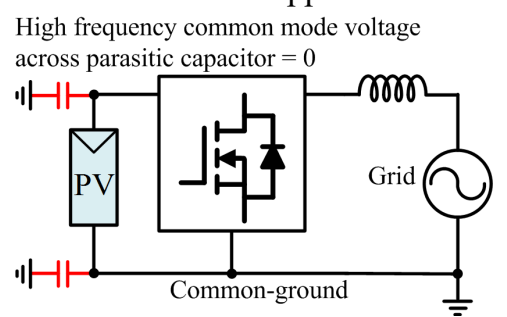

Fig. 1. Common-ground transformerless inverter for leakage current suppression.

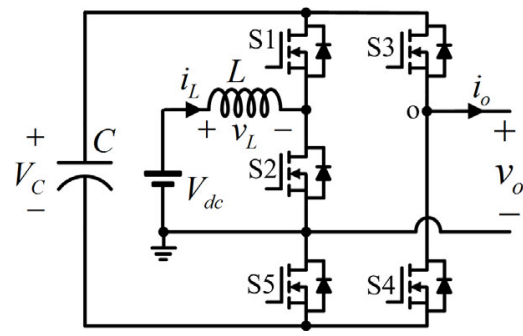

Fig. 2. The latest single-stage common-ground transformerless inverter with voltage boosting capability [10]. 
This letter proposes a new pulse width modulation (PWM) technique to realize a continuous input current in the aforementioned topology, whilst retaining all good traits. This results in smooth, continuous and reduced peak input current, whilst producing a good quality ac output voltage. The rest of the letter is organized as follows: section II presents the proposed PWM technique, section III discusses simulation comparison, section IV presents the experimental results for validation, and finally section $\mathrm{V}$ draws the conclusion.

\section{Proposed PWM TeChNiQue}

Low frequency input current ripple is induced in a single phase inverter due to its power pulsation at double fundamental frequency. The PWM technique presented in [10] further aggravates this issue since the boost inductor is operated in discontinuous current mode with extremely high peak current. To resolve this problem, the input inductor $L$ should be operated (charging and discharging) with a constant duty-cycle. Analysis in Table I shows that $L$ can only be discharged during $0 \mathrm{~V}$. Therefore, the maximum discharging duty-cycle for $L$ should be constrained to the minimum duty-cycle of $v_{0}=0 \mathrm{~V}$. Based on this consideration, a new PWM technique in Fig. 3 is established.

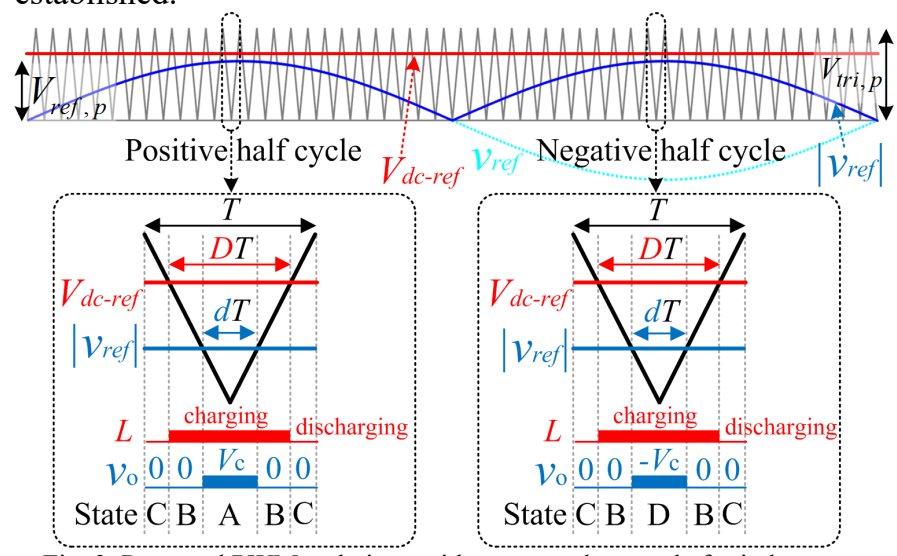

Fig. 3. Proposed PWM technique with constant duty-cycle for inductor to achieve continuous input current.

TABLE I

ANALYSIS OF SWITCHING STATES

\begin{tabular}{cccc}
\hline \hline State & $\begin{array}{c}\text { Switch condition } \\
\text { (S1 S2 S3 S4 S5) }\end{array}$ & $\begin{array}{c}\text { Inductor, } \\
\boldsymbol{L}\end{array}$ & $\begin{array}{c}\text { Output voltage, } \\
\boldsymbol{v}_{\mathbf{0}}\end{array}$ \\
\hline \hline A & 01101 & Charging & $+V_{\mathrm{C}}$ \\
B & 01011 & Charging & 0 \\
C & 10011 & Discharging & 0 \\
D & 11010 & Charging & $-V_{\mathrm{C}}$ \\
Switch condition: $1=\mathrm{ON}, 0=$ OFF & &
\end{tabular}

Noting that two references and one triangular carrier are used to control the inverter. A constant duty-cycle can be generated by comparing a constant reference $V_{\text {dc-ref }}$ with the triangular carrier as:

$$
D=\frac{V_{d c-r e f}}{V_{t r i, p}}
$$

where $D$ denotes the charging duty-cycle of input inductor $L$. Considering the volt-second balance of the input inductor $L$, the average voltage across the capacitor $C$ can be obtained as

$$
V_{C}=\frac{1}{1-D} V_{d c}
$$

Duty-cycle generated by the sinusoidal reference can be written as a function of time,

$$
d=M|\sin (\omega t)|
$$

where $M=V_{\text {ref,p }} / V_{\text {tri,p }}$ indicates the modulation index. The fundamental output voltage is expressed as

$$
v_{o, 1}=\left\{\begin{array}{l}
d V_{C}, 0<\omega t<\pi \\
-d V_{C}, \pi<\omega t<2 \pi
\end{array}=M V_{C} \sin (\omega t)\right.
$$

The peak of fundamental output voltage can be obtained by substituting (2) into (4),

$$
V_{o, 1, p}=M V_{C}=M \frac{1}{1-D} V_{d c}
$$

Therefore, the gain of the inverter is

$$
G=\frac{V_{o, 1, p}}{V_{d c}}=\frac{M}{1-D}
$$

As the minimum $V_{\text {dc-ref }}$ is constrained to $V_{\text {ref,p }}$, the minimum $D$ is thus equal to $M$, i.e. $D_{\min }=M$ with a critical gain of $M /(1-M)$, which is same as presented in [10]. This shows the voltage boosting capability of the converter is unaffected whilst achieving the continuous input current, which is very critical for PV applications.

\section{SimULATION COMPARISON}

Simulation study has been conducted to evaluate the performance of both the existing and proposed PWM schemes. For fair comparison, same parameters are used for both schemes. To produce $120 \mathrm{~V}(\mathrm{rms})$, the modulation index of both simulations were set to 0.63 .

Fig. 4 shows that the ac output waveform generated by both PWM techniques are similar. However, the magnitude of ac output generated by [10] is only $105 \mathrm{~V}(\mathrm{rms})$ which is less than the theoretical calculation of $120 \mathrm{~V}$ (rms). Due to variable charging duty-cycle for inductor, the voltage gain equation is less accurate. In addition, it is evident that the existing PWM technique [10] as shown in Fig. 4(a) results in discontinuous inductor current with extremely high peak current which may adversely affect the converter as well as PV sources.

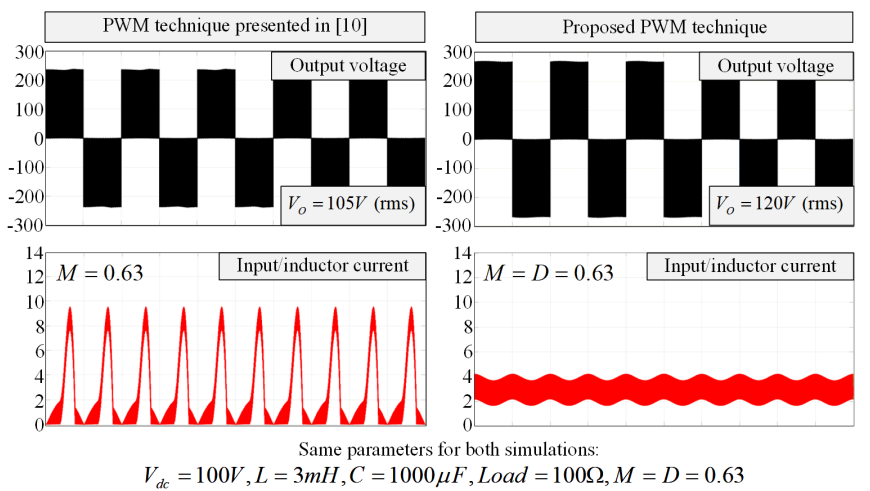

(a)

(b)

Fig. 4. Comparison of the input current with (a) a conventional PWM method [10], and (b) the proposed PWM technique.

On the other hand, the proposed PWM technique as shown in Fig. 4(b) generates accurate ac voltage of $120 \mathrm{~V}$ (rms). It offers continuous inductor current with relatively constant current ripple. This is beneficial for PV applications since high input power fluctuation is no longer a concern and thus little effort is needed to remove the power ripple in the input side of 
the inverter. Moreover, effective attenuation of the peak current indicates reduced current stress on switching devices.

This work has contributed to an improved PWM technique as an alternative for [10]. Control schemes for further reduction in second harmonic current can be referred to comprehensive studies presented in [11], [12].

\section{Simulation AND EXPERIMENTAL RESUlts}

To validate the proposed PWM technique, an experimental prototype was built. The experimental setup and parameters used for implementation can be found in Fig. 5 and Table II respectively. Fig. 6 shows the experimental results conducted at $M=0.6$ when the load is purely resistive. It can be seen that the load current is proportional with the ac voltage. With the input voltage of $100 \mathrm{~V}(\mathrm{dc})$ and output voltages of $120 \mathrm{~V}(\mathrm{rms})$, the measured gain is approximately 1.7 , which matches well with the theoretical calculation in (6). Sinusoidal load current is observed when the experiment was repeated for series resistorinductor (RL) load, as shown in Fig. 7. Besides, it is also clearly demonstrated from Fig. 8 that the load current changes instantaneously when the load was switched from RL to purely resistive load.

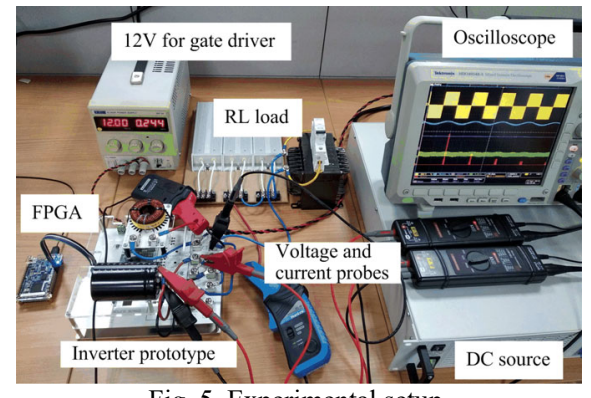

Fig. 5. Experimental setup.

TABLE II

PARAMETERS OF EXPERIMENTAL PROTOTYPE

\begin{tabular}{cc}
\hline \hline Symbol & Value \\
\hline \hline$V_{\mathrm{dc}}$ & $30-100 \mathrm{~V}$ \\
$V_{\mathrm{O}}$ & $120 \mathrm{~V}(\mathrm{RMS})$ \\
$L$ & $3 \mathrm{mH}$ \\
$C$ & $1000 \mu \mathrm{F}$ \\
$D$ & $1.1 * M$ \\
Carrier frequency & $10 \mathrm{kHz}$ \\
Load resistor & $100 \Omega$ \\
Load inductor & $100 \mathrm{mH}$ \\
\hline \hline
\end{tabular}

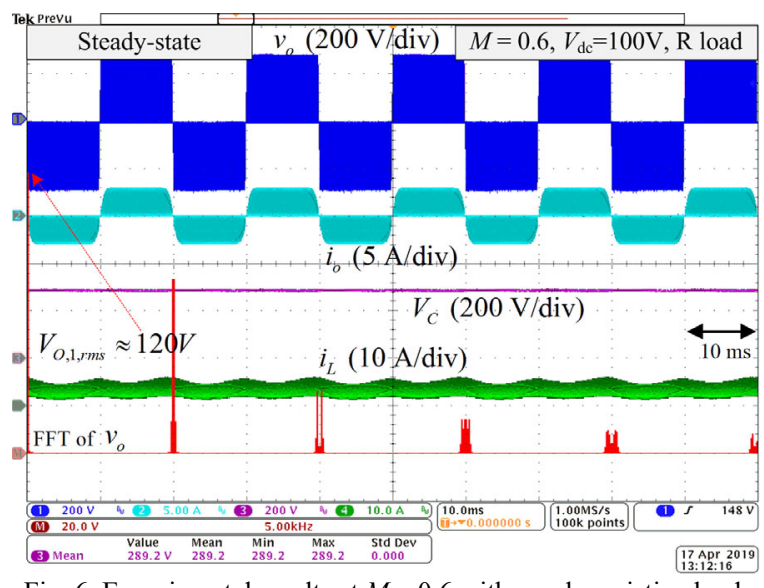

Fig. 6. Experimental results at $M=0.6$ with purely resistive load.

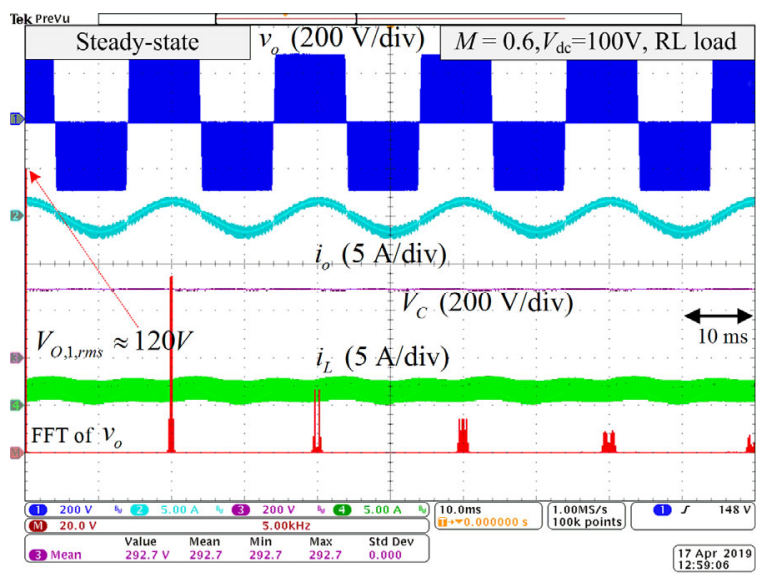

Fig. 7. Experimental results at $M=0.6$ with resistive-inductive load.

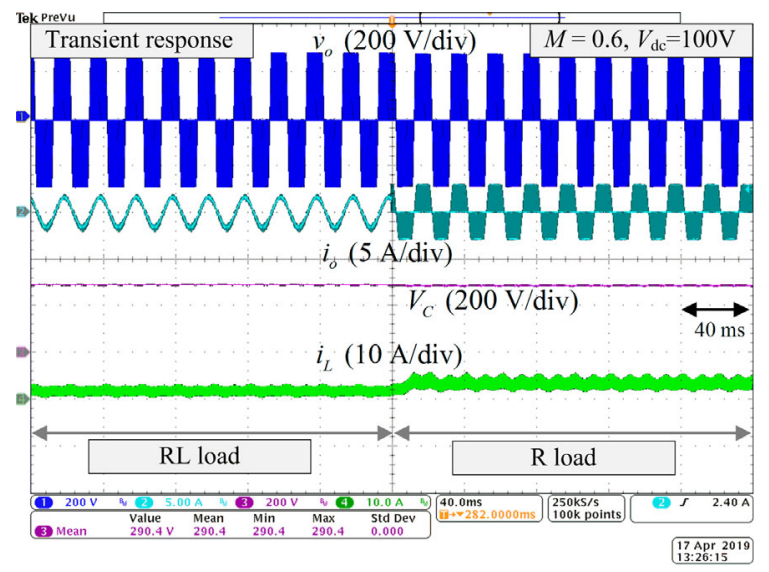

Fig. 8. Experimental results at $M=0.6$ during step load transient.

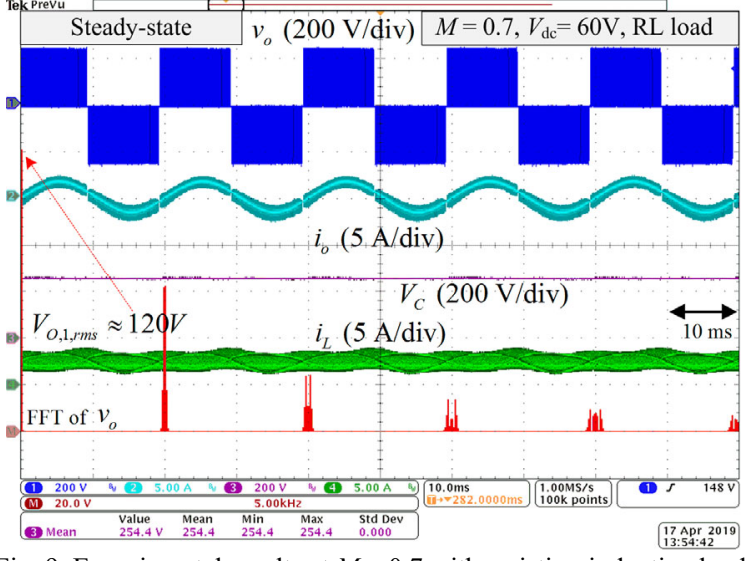

Fig. 9. Experimental results at $M=0.7$ with resistive-inductive load.

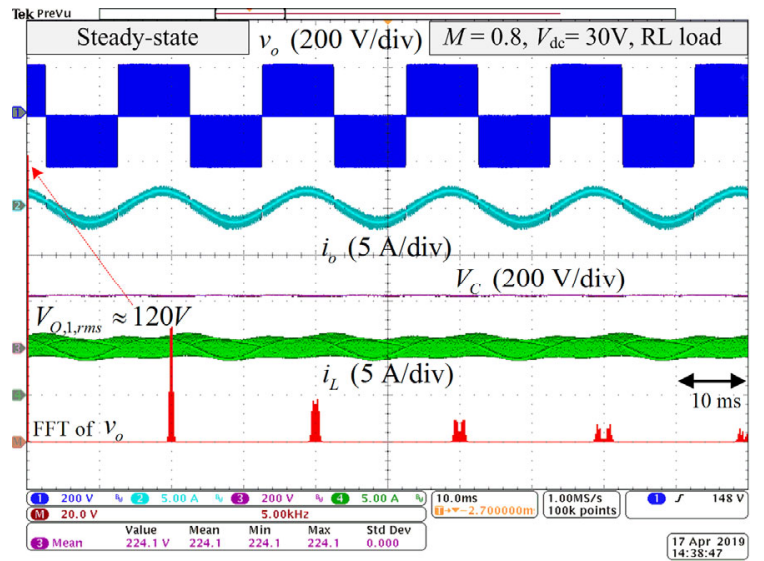

Fig. 10. Experimental results at $M=0.8$ with resistive-inductive load. 
Further tests on the performance at different modulation indexes were then carried out. By increasing $M$ to 0.7, Fig. 9 depicts that higher gain can be achieved. Even higher gain of 5.6 is anticipated when $M$ is increased to 0.8 that generates 120 $\mathrm{V}$ (rms) from the input dc voltage of only $30 \mathrm{~V}$, as shown in Fig. 10.

It is also mentioned that the modulation technique implemented in [10] is not capable for high modulation index, where it limits the voltage gain to 4 only. However, this problem is resolved in the proposed PWM technique as proven by the achievement of higher voltage gain values. Observations from all the experimental results shows that the input current of the inverter is continuous and smooth, which again proves the effectiveness of the proposed PWM technique.

A simulation in Fig. 11 was also conducted to validate the inverter operation for grid connected application. Observation shows that the grid current is in phase with the grid voltage when active power flows from dc source to the grid. In the case of rectification mode where active power flows in opposite direction, it is obvious that the grid current is out of phase with the grid voltage.

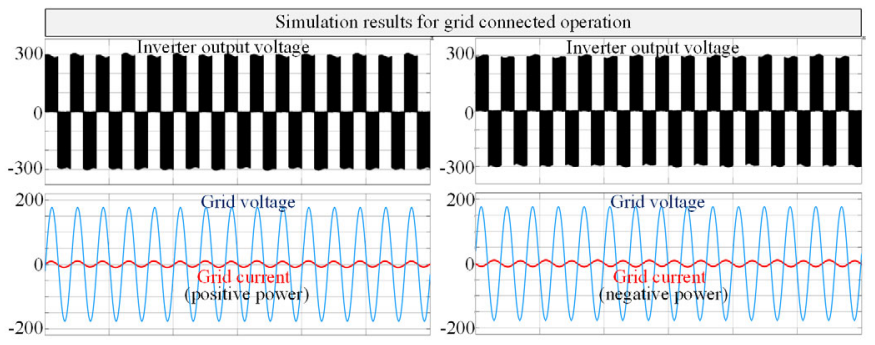

Fig. 11. Simulation results for grid connected operation.

\section{CONCLUSION}

This letter has proposed a new PWM technique for a common-ground transformerless boost inverter which features single-stage power conversion. Aiming an improvement in the input current performance, the proposed PWM technique charges the input inductor with a constant duty-cycle while generating a good quality ac voltage at the output. Continuous input current is achieved while the high peak current and input power fluctuation are eliminated. Good agreement among analysis, simulation and experimental results have validated the contributions and feasibility of the proposed PWM technique.

\section{REFERENCES}

[1] S. Kouro, J. I. Leon, D. Vinnikov, and L. G. Franquelo, "Grid-Connected Photovoltaic Systems: An Overview of Recent Research and Emerging PV Converter Technology," IEEE Ind. Electron. Mag., vol. 9, no. 1, pp. 4761, 2015.

[2] M. N. H. Khan, M. Forouzesh, Y. P. Siwakoti, L. Li, T. Kerekes, and F. Blaabjerg, "Transformerless Inverter Topologies for Single-Phase Photovoltaic Systems: A Comparative Review," IEEE J. Emerg. Sel. Top. Power Electron., 2019.

[3] G. E. Valderrama, G. V. Guzman, E. I. Pool-Mazún, P. R. MartinezRodriguez, M. J. Lopez-Sanchez, and J. M. S. Zuñiga, "A Single-Phase Asymmetrical T-Type Five-Level Transformerless PV Inverter," IEEE $J$. Emerg. Sel. Top. Power Electron., vol. 6, no. 1, pp. 140-150, 2018.

[4] J. F. Ardashir, M. Sabahi, S. H. Hosseini, F. Blaabjerg, E. Babaei, and G. B. Gharehpetian, "A Single-Phase Transformerless Inverter With Charge Pump Circuit Concept for Grid-Tied PV Applications," IEEE Trans. Ind. Electron., vol. 64, no. 7, pp. 5403-5415, 2017.

[5] Y. P. Siwakoti and F. Blaabjerg, "Common-Ground-Type Transformerless Inverters for Single-Phase Solar Photovoltaic Systems," IEEE Trans. Ind.
Electron., vol. 65, no. 3, pp. 2100-2111, 2018

[6] F. B. Grigoletto, "Five-Level Transformerless Inverter for Single-Phase Solar Photovoltaic Applications," IEEE J. Emerg. Sel. Top. Power Electron., 2019.

[7] M. S. W. Chan and K. T. Chau, "A New Switched-Capacitor Boost Multilevel Inverter Using Partial Charging," IEEE Trans. Circuits Syst. II Express Briefs, vol. 54, no. 12, pp. 1145-1149, 2007.

[8] S. S. Lee, C. S. Lim, Y. P. Siwakoti, and K.-B. Lee, "Hybrid 7-Level Boost Active-Neutral-Point-Clamped (H-7L-BANPC) Inverter," IEEE Trans. Circuits Syst. II Express Briefs, Early Access, 2019.

[9] M. J. Sathik, N. Sandeep, and F. Blaabjerg, "High Gain Active Neutral Point Clamped Seven-Level Self-Voltage Balancing Inverter," IEEE Trans. Circuits Syst. II Express Briefs, Early Access, 2019.

[10]X. Hu, P. Ma, B. Gao, and M. Zhang, "An Integrated Step-Up Inverter Without Transformer and Leakage Current for Grid-Connected Photovoltaic System," IEEE Trans. Power Electron., vol. 34, no. 10, pp. 9814-9827, 2019.

[11]L. Zhang, X. Ruan, and X. Ren, "Second-Harmonic Current Reduction for Two-Stage Inverter With Boost-Derived Front-End Converter: Control Schemes and Design Considerations," IEEE Trans. Power Electron., vol. 33, no. 7, pp. 6361-6378, 2018.

[12]L. Zhang and X. Ruan, "Control Schemes for Reducing Second Harmonic Current in Two-Stage Single-Phase Converter: An Overview From DCBus Port-Impedance Characteristics," IEEE Trans. Power Electron., vol. 33, no. 10, pp. 10341-10358, 2019. 